\title{
Performance evaluation of a gas fired boiler in commercial dairy plant
}

\section{D.A. CHAUDHARY AND A.G. CHAUDHARI}

\begin{abstract}
Boiler is one of the most important components for dairy processing plant because which provide heating medium as steam at rate of required quantity with optimum quality .The present work is an account of "Performance Evaluation Of A Gas Fired Boiler- A Case Study In commercial Dairy Industry “. The study was aimed at assessing the operational performance of the gas fired boiler by evaluating the thermal efficiency and evaporation ratio. The analysis was carried out and found that the boiler having capacity of $501.6 \mathrm{~kg}$ steam production per hour at $6.8 \mathrm{~kg} / \mathrm{cm}^{2}$ with the help of natural gas consumption of $45.56 \mathrm{~m}^{3} \mathrm{OR} 27.33$ $\mathrm{kg}$. Evaporation ratio was obtained 18.35 per $1 \mathrm{~kg}$ of natural gas and 11 per $1 \mathrm{~m}^{3}$ of natural gas utilized. The thermal efficiency determined by direct method and indirect method was 72.75 per cent and 68.29 , respectively. The cost for one $\mathrm{kg}$ steam production was obtained 1.866 Rupees.
\end{abstract}

KEY WORDS : Boiler, Evaporation ratio, Thermal efficiency, Steam, Natural gas

How TO CITE THIS PAPER : Chaudhary, D.A. and Chaudhari, A.G. (2015). Performance evaluation of a gas fired boiler in commercial dairy plant. Res. J. Animal Hus. \& Dairy Sci., 6(2) : 158-164.

\section{MEMBERS OF RESEARCH FORUM}

Address for correspondence :

D.A. Chaudhary, Department of Dairy Engineering, SMC College of Dairy Science, ANAND (GUJARAT) INDIA

Email : dchaudhary89@gmail.com

Associated Authors':

A.G. Chaudhari, Department of Dairy Engineering, SMC College of Dairy Science, ANAND (GUJARAT) INDIA 